\section{Industry and academic partnership celebrates 50th anniversary}

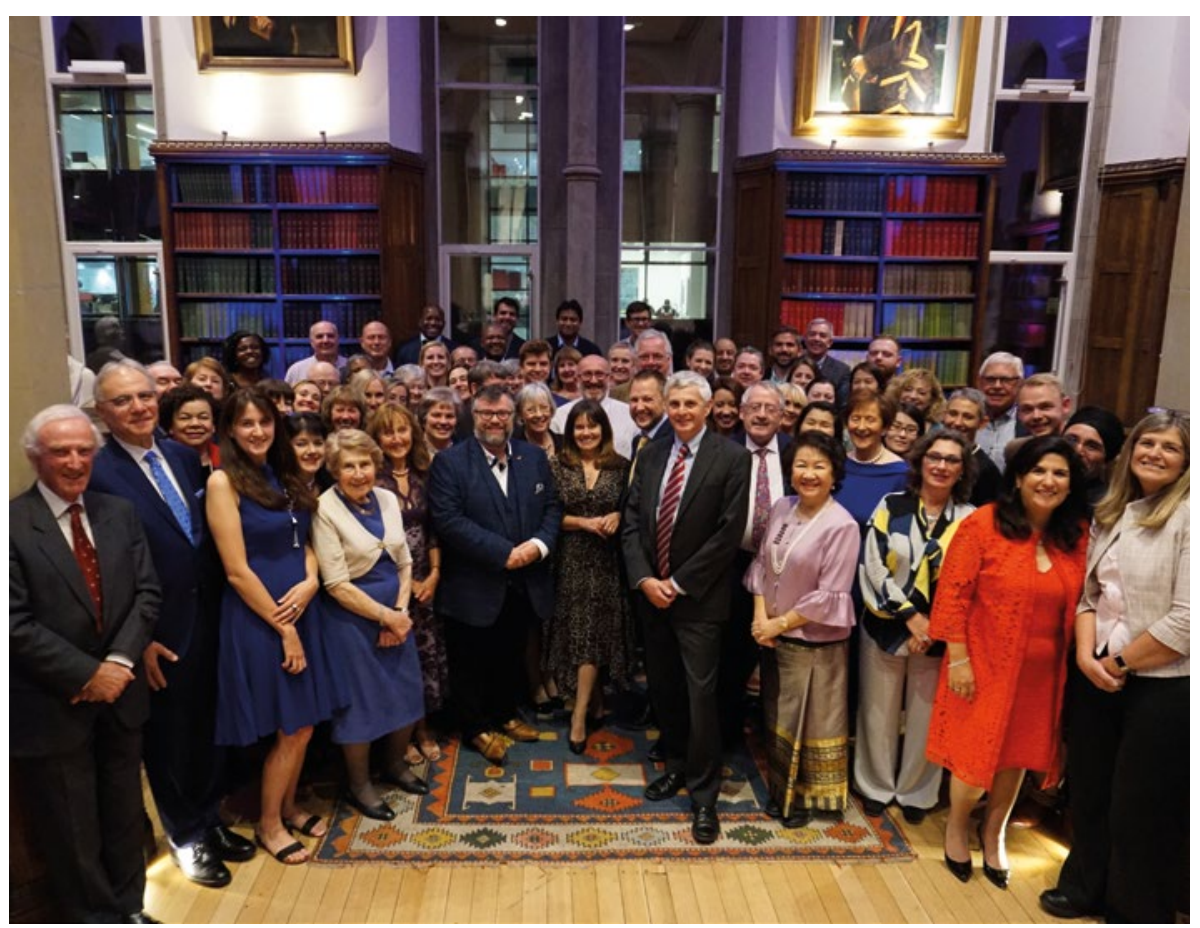

An unusual collaboration between industry and academia has celebrated its fiftieth anniversary.

An event was held on 28 September 2018 in Manchester when the Colgate Dental Health Unit (DHU) marked its fiftieth anniversary and celebrated the enduring partnership between Colgate-Palmolive and the University of Manchester.

The DHU is described as a unique collaboration between industry and academia with the overarching aim of improving dental public health and oral care research methodologies.

Attendees at the event included many of the alumni and staff from the past 50 years, travelling from as far afield as the USA, India, and Thailand, including the first Dental Health Unit PhD student Professor Andrew Rugg-Gunn as well as senior leadership from the Colgate-Palmolive Company, including Chief Technology Officer Dr Pat Verduin.

Attendees celebrated the event with an afternoon symposium reminiscing over the past 50 years of dental research, education and clinical practice as well as some optimistic speculation on what the next 50 years will hold. The day ended with a celebratory dinner at the University's Christie’s Bistro.

\section{Dentists invited to get involved in research}

Dental professionals who might be interested and willing to get involved in research are being invited to complete a survey that could help boost the profession's role in this area.

A survey has been developed by the National Institute for Health Research's (NIHR) Clinical Research Network Oral and Dental Health Specialty Group, supported by the Chief Dental Officers of the four UK nations, the Faculty of General Dental Practitioners, the Dental Schools Council and the British Society for Oral and Dental Research.

The survey, called Developing the Oral and Dental Research Workforce, ${ }^{1}$ is designed to identify dentists and dental care professionals who are interested in taking part in research and to describe practice characteristics and readiness to take part.

The work follows on from a project to identify the top ten unanswered questions relating to oral and dental health research from a patient, public and clinical perspective.

Organisers have begun engaging with funding bodies about funding research within the identified priorities. The new survey will allow for the next step - to understand the workforce currently available to develop and deliver oral health research and how to strengthen it.

\section{References}

1. NIHR. Developing the Oral and Dental Research Workforce. Available at https://docs.google.com/ forms/d/e/1FAlpQLSCOAb-lq2E_EGOsygduOeZ6IOJFddq3TixgoDxcjP_xTzZh3Q/viewform (accessed February 2019).

\title{
Invitation to innovative dentists and DCPS
}

Any dentists and dental care professionals (DCPs) who are developing or plan to embrace clinical innovations or enterprises in the dental profession are being invited to become participants in what is being described as a prestigious scheme now in its fourth year.

Professionals can now apply to join the Clinical Entrepreneur Training Programme and applications are open from 4 to 29 March 2019. The programme will start in autumn 2019.

Managed jointly by NHS England,

Health Education England and endorsed by the Chief Dental Officer for England Sara Hurley, the scheme is a result of intensive work with entrepreneurial clinicians, academic leaders and industry partners.

The scheme includes:

- A mentoring and coaching scheme

- Customer matching

- Possible entrepreneurial placements/ internships

- Time for entrepreneurial activity such as less than full time, annualised job planning, time out from clinical duties.

More information is available at https://www.england.nhs.uk/ourwork/ innovation/clinical-entrepreneur/ and any enquiries can be emailed to Shan Ellahi at sellahi@nhs.net. 